\title{
ФОРМИРОВАНИЕ ИНВАЗИОННОГО КОМПОНЕНТА ФЛОРЫ БЕЛГОРОДСКОЙ ОБЛАСТИ ЗА 170 ЛЕТ
}

\author{
(C) 2020 г. В. К. Тохтарь ${ }^{1, *}$, А. Ю. Курской ${ }^{1, * *}$ \\ ${ }^{1}$ Белгородский государственный национальный исследовательский университет \\ ул. Победы, 85, Белгород, 308015, Россия \\ *e-mail:tokhtar@bsu.edu.ru \\ **e-mail: kurskoy@bsu.edu.ru \\ Поступила в редакцию 25.03.2020 г. \\ После доработки 13.05.2020 г. \\ Принята к публикации 19.05.2020 г.
}

\begin{abstract}
С 2011 по 2019 гг. было исследовано свыше 200 природных местообитаний растений и выявлен инвазионный компонент флоры Белгородской области (всего 78 видов). На основании исследования гербарных образцов 12 гербариев установлено, что появление видов, которые на современном этапе развития флоры региона стали инвазионными, происходило неравномерно. Динамика появления инвазионных видов условно разделена авторами на три этапа: 1. Появление чужеродных видов (1850-1929 гг.); 2. Первоначальная адаптация и распространение чужеродных растений (1930-1989 гг.); 3. Интенсификация заноса и инвазии видов (1990-2019 гг.). За 170-летний период произошли существенные изменения в соотношениях различных групп инвазионных видов. Перестройки в структуре инвазионного компонента флоры связаны в первую очередь с антропогенным воздействием на природные экосистемы.
\end{abstract}

Ключевые слова: юго-запад Среднерусской возвышенности, Белгородская область, инвазионные виды DOI: $10.31857 / \mathrm{S} 0006813620090094$

Изучение инвазий растений является одним из наиболее приоритетных направлений современных ботанических и экологических исследований, поскольку чужеродные виды могут наносить значительный экономический ущерб и даже представлять опасность для здоровья людей. Усиление антропогенного воздействия на флору приводит к стиранию природных границ, нарушению зональных условий формирования фитобиоты, что способствует интенсификации распространения чужеродных видов (Richardson et al., 2007; Vinogradova et al., 2010, 2011, 2018; Blackburn et al., 2011; Baranova et al., 2016; Senator et al., 2017).

За последние 11 лет нами впервые зарегистрировано появление во флоре региона более 30 -ти видов, в частности: Amaranthus cruentus L., Amelanchier spicata (Lam.) C. Koch, Anisantha sterilis (L.) Nevski, Asclepias syriaca L., Cenchrus longispinus (Hack.) Fernald, Campanula $\times$ spryginii Saksonov et Tzvelev, Centaurea montana L., Chenopodium betaceum Andrz., Commelina communis L., Datura inoxia Mill., Dipsacus fullonum L., Euphorbia davidii Subils, E. marginata Pursh, Grindelia squarrosa (Pursh) Dunal, Heracleum sosnowskyi Manden., Hordeum murinum L., Impatiens parviflora DC., Jurinea charcovi- ensis Klokov, Lupinus polyphyllus Lindl., Melampyrum polonicum (Beauv.) Soo, Nicotiana rustica, Oenothera oakesiana (A. Gray) Robbins. ex S. Watson, O. depressa Greene, O. glazioviana Micheli, O. macrocarpa Nutt, Onobrychis tanaitica Spreng., Panicum capillare L., P. dichotomiflorum Michx., Physalis philadelphica Lam., Ptelea trifoliata L., Thladiantha dubia Bunge, Veronica polita Fries, Potentilla bifurca L. и др. (Tokhtar, Fomina, 2013; Tokhtar et al., 2019; Tokhtar, Kurskoi, 2019).

Целью данного исследования было установление формирования инвазионного компонента флоры юго-запада Среднерусской возвышенности за последние 170 лет.

\section{МАТЕРИАЛЫ И МЕТОДЫ}

Для выявления инвазионного компонента флоры с 2011 по 2019 гг. было исследовано свыше 200 природных местообитаний региона, в том числе на 27 особо охраняемых природных территориях, в которых произрастали чужеродные растения. Предварительно для выявления инвазионного компонента флоры нами за основу был взят список чужеродных видов растений Средней России (Vinogradova et al., 2010) и региональный кон- 


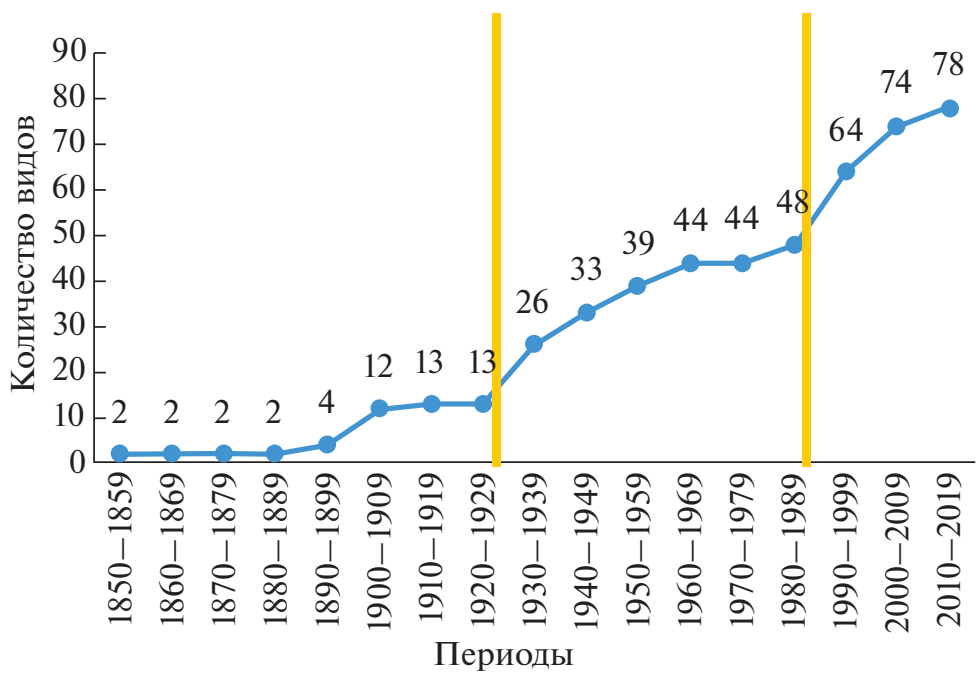

Рис. 1. Динамика появления инвазионных видов растений на юго-западе Среднерусской возвышенности. Fig. 1. Dynamics of the appearance of invasive plant species in the southwest of the Central Russian Upland.

спект флоры (Elenevskii et al., 2004), которые проверялись в ходе экспедиционных выездов с учетом разработанных Ю.К. Виноградовой с соавторами (Vinogradova et al., 2010) критериев для выделения инвазионных видов. Таким образом был выявлен видовой состав чужеродных растений (всего 78 видов). Эти виды исследовались нами для выявления формирования группы инвазионных растений с момента их появления в регионе до настоящего времени. Исследования проводились маршрутным способом, позволившим охватить все разнообразие экотопов, в которых встречаются эти растения.

Для установления времени появления инвазионных видов во флоре региона были изучены материалы гербарных коллекций гербариев LE, MHA, MW, OHHI, VOR, VU, WIR, BELZ, BSU, гербариев кафедры геоботаники и экологии Санкт-Петербургского государственного университета, Центрально-Черноземного заповедника имени В.В. Алехина (г. Курск), Научно-образовательного центра "Ботанический сад НИУ "БелГУ" (г. Белгород). Для каждого вида было установлено предполагаемое время его появления и степень натурализации в регионе.

\section{РЕЗУЛЬТАТЫ}

Сравнение гербарных данных за 170-летний период времени свидетельствует о том, что видовой состав инвазионного компонента флоры юго-запада Среднерусской возвышенности существенно увеличился (рис. 1). Анализ полученных сведений позволил нам выявить несколько пиков активности в появлении чужеродных видов растений на территории юго-запада Среднерусской возвышенности. Весь процесс появле- ния инвазионных видов на исследованной территории условно можно разделить на три периода:

1. Появление чужеродных видов (1850-1929 гг.);

2. Первоначальная адаптация и распространение чужеродных растений (1930-1989 гг.);

3. Интенсификация заноса и инвазия видов (1990-2019 гг.).

Эти периоды отличаются друг от друга не только продолжительностью, но и количеством видов, родов и семейств, появившихся в разное время в регионе.

Изменения в таксономическом составе инвазионных растений, по-видимому, связаны как с интенсификацией заноса растений в разные периоды времени: увеличением количества нарушенных местообитаний (распашка территорий, расширение сети техногенных экотопов), так и с периодами активности изучения флоры разными исследователями.

Продолжительность первого периода составляет 79 лет. За это время число инвазионных видов увеличилось с одного до тринадцати (табл. 1). Их находки на территории региона отмечались участниками экспедиций Императорской Академии наук (Ф.М. Августинович, К.С. Горницкий, А. Славгородский, Б.Ф. Кашменский, И.М. Паллон, А.И. Мальцев.) Первыми видами были собранные в июне 1859 г. Oenothera biennis L. (г. Новый Оскол, MW 0449001) и Kochia scoparia (L.) Schrad. (LE). На первом этапе инвазионный комплекс включал 3 вида сем. Poaceae, Chenopodiaceae (2 вида) и по одному из семейств Amaranthaceae, Araceae, Asteraceae, Brassicaceae, Fabaceae, Lamiaceae, Onagraceae и Solanaceae. Большинство видов, появившихся в регионе в этот период времени, относятся к однолетникам и травянистым 
Таблица 1. Соотношения эколого-биоморфологических характеристик инвазионных видов растений на разных этапах их появления в регионе

Table 1. Ratio of ecological-and-biomorphological characteristics of invasive plant species at different stages of their appearance in the region

\begin{tabular}{|c|c|c|c|c|}
\hline \multirow{3}{*}{$\begin{array}{l}\text { Группа растений } \\
\text { Plant groups }\end{array}$} & \multicolumn{4}{|c|}{$\begin{array}{l}\text { Этапы появления инвазионных видов } \\
\text { Stages of appearance of invasive species }\end{array}$} \\
\hline & I & II & III & Итого \\
\hline & $\begin{array}{c}\text { Число видов } \\
\text { Number of species }\end{array}$ & $\begin{array}{c}\text { Число видов } \\
\text { Number of species }\end{array}$ & $\begin{array}{c}\text { Число видов } \\
\text { Number of species }\end{array}$ & $\begin{array}{c}\text { Число видов } \\
\text { Number of species }\end{array}$ \\
\hline \multicolumn{5}{|c|}{$\begin{array}{l}\text { Жизненные формы по И.Г. Серебрякову (1962) } \\
\text { Life forms according to I.G. Serebryakov (1962) }\end{array}$} \\
\hline $\begin{array}{l}\text { Однолетники } \\
\text { Annual plants }\end{array}$ & 7 & 9 & 11 & 27 \\
\hline $\begin{array}{l}\text { Травянистые поликарпики } \\
\text { Polycarpic herbs }\end{array}$ & 4 & 4 & 10 & 18 \\
\hline $\begin{array}{l}\text { Травянистые монокарпики } \\
\text { Monocarpic herbs }\end{array}$ & 1 & 3 & 2 & 6 \\
\hline $\begin{array}{l}\text { Кустарники } \\
\text { Bushes }\end{array}$ & 1 & 10 & 2 & 13 \\
\hline $\begin{array}{l}\text { Деревья } \\
\text { Trees }\end{array}$ & 0 & 9 & 5 & 14 \\
\hline
\end{tabular}

По типу корневой системы

By type of root system

\begin{tabular}{|c|c|c|c|c|}
\hline $\begin{array}{l}\text { Стержневая } \\
\text { Taproot }\end{array}$ & 9 & 28 & 23 & 60 \\
\hline $\begin{array}{l}\text { Кистевая } \\
\text { Fibrous root }\end{array}$ & 2 & 0 & 3 & 5 \\
\hline $\begin{array}{l}\text { Стержнекистевая } \\
\text { Tap-and-fibrous root }\end{array}$ & 0 & 3 & 1 & 4 \\
\hline $\begin{array}{l}\text { Без корней } \\
\text { Without roots }\end{array}$ & 2 & 4 & 3 & 9 \\
\hline
\end{tabular}

По отношению к условиям увлажнения

By relation to moisture conditions

\begin{tabular}{|c|c|c|c|c|}
\hline $\begin{array}{l}\text { Ксеромезофиты } \\
\text { Xeromesophytes }\end{array}$ & 9 & 8 & 7 & 24 \\
\hline $\begin{array}{l}\text { Мезоксерофиты } \\
\text { Mesoxerophytes }\end{array}$ & 1 & 5 & 4 & 10 \\
\hline $\begin{array}{l}\text { Гидрофиты } \\
\text { Hydrophytes }\end{array}$ & 1 & 1 & 2 & 4 \\
\hline $\begin{array}{l}\text { Гигрофиты } \\
\text { Hygrophytes }\end{array}$ & 0 & 0 & 1 & 1 \\
\hline $\begin{array}{l}\text { Эумезофиты } \\
\text { Eumosophytes }\end{array}$ & 2 & 20 & 16 & 38 \\
\hline $\begin{array}{l}\text { Эуксерофиты } \\
\text { Euxerophytes }\end{array}$ & 0 & 1 & 0 & 1 \\
\hline
\end{tabular}

По географическому происхождению видов

By geographic origin of species

\begin{tabular}{|c|c|c|c|c|}
\hline $\begin{array}{l}\text { Азиатские } \\
\text { Asiatic }\end{array}$ & 6 & 1 & 5 & 12 \\
\hline $\begin{array}{l}\text { Североамериканские } \\
\text { North American }\end{array}$ & 3 & 14 & 13 & 30 \\
\hline
\end{tabular}


Таблица 1. Окончание

\begin{tabular}{|c|c|c|c|c|}
\hline \multirow{3}{*}{$\begin{array}{l}\text { Группа растений } \\
\text { Plant groups }\end{array}$} & \multicolumn{4}{|c|}{$\begin{array}{l}\text { Этапы появления инвазионных видов } \\
\text { Stages of appearance of invasive species }\end{array}$} \\
\hline & I & II & III & Итого \\
\hline & $\begin{array}{c}\text { Число видов } \\
\text { Number of species }\end{array}$ & $\begin{array}{c}\text { Число видов } \\
\text { Number of species }\end{array}$ & $\begin{array}{c}\text { Число видов } \\
\text { Number of species }\end{array}$ & $\begin{array}{c}\text { Число видов } \\
\text { Number of species }\end{array}$ \\
\hline $\begin{array}{l}\text { Средиземноморские } \\
\text { Mediterranean }\end{array}$ & 3 & 3 & 1 & 7 \\
\hline $\begin{array}{l}\text { Европейские } \\
\text { European }\end{array}$ & 1 & 14 & 5 & 20 \\
\hline $\begin{array}{l}\text { Сибирские } \\
\text { Siberian }\end{array}$ & 0 & 2 & 1 & 3 \\
\hline $\begin{array}{l}\text { Кавказские } \\
\text { Caucasian }\end{array}$ & 0 & 1 & 1 & 2 \\
\hline $\begin{array}{l}\text { Южноамериканские } \\
\text { South American }\end{array}$ & 0 & 0 & 2 & 2 \\
\hline $\begin{array}{l}\text { Восточно-понтические } \\
\text { Eastern Pontic }\end{array}$ & 0 & 0 & 1 & 1 \\
\hline $\begin{array}{l}\text { Причерноморско-прикаспийские } \\
\text { Black Sea-Caspian }\end{array}$ & 0 & 0 & 1 & 1 \\
\hline \multicolumn{5}{|c|}{$\begin{array}{c}\text { По способу заноса } \\
\text { By the way of introduction }\end{array}$} \\
\hline $\begin{array}{l}\text { Ксенофиты } \\
\text { Xenophytes }\end{array}$ & 10 & 18 & 18 & 46 \\
\hline $\begin{array}{l}\text { Эргазиофиты } \\
\text { Ergasiophytes }\end{array}$ & 3 & 17 & 12 & 32 \\
\hline $\begin{array}{l}\text { Bсего: } \\
\text { Total: }\end{array}$ & 13 & 35 & 30 & 78 \\
\hline
\end{tabular}

поликарпикам, а по географическому происхождению в этой группе представлены азиатские, североамериканские и средиземноморские виды (табл. 1).

Второй период по количеству вновь занесенных видов превзошел предыдущий более чем в 2.5 раза. Количество семейств в спектре инвазионного компонента флоры региона к 1989 г. увеличилось с 10 до 16. Именно в этот период появляются виды, которые в настоящее время отнесены нами к трансформерам: Acer negundo L. (впервые отмечен в 1935 г.), Fraxinus pennsylvanica Marshall (1936 г.), Amorpha fruticosa L. (1937 г.), Robinia pseudoacacia L. (1938 г.).

Сравнительный анализ растений, занесенных в регион на первом и втором этапах, свидетельствует о том, что в спектре семейств происходит увеличение представителей семейств Rosaceae (на 5 видов), Asteraceaе и Brassicaceae (на 4 вида каждое), Caprifoliaceae и Oleaceae (на 3 вида каждое), Fabaceae (на 2 вида), Amaranthaceae (на 1 вид). Впервые на этом этапе появляются единичные представители семейств Aceraceae, Berberidaceae,
Cuscutaceae, Elaeagnaceae, Grossulariaceae, Hydrocharitaceae, Portulacaceae, Vitaceae.

Происходило увеличение количества деревьев и кустарников (на 9 видов в каждой группе), травянистых монокарпиков (на 3 вида) и однолетников (на 2 вида). Впервые появляется ксерофит Kibera gallica (Willd.) V.I. Dorof. (1956 г., VU), на 13 видов увеличивается число европейских видов и на 11 - североамериканских, однако на 5 видов уменьшается число азиатских. Зарегистрированы также сибирские Caragana arborescens Lam. (1938 г., BELZ), Lonicera tatarica L. (1938 г., BELZ) и кавказский вид - Prunus cerasifera Ehrh. (1949 г., BELZ).

Третий временной отрезок (1989-2019 гг.) является самым коротким, однако практически половина занесенных в регион инвазионных видов (30 из 78) появилась именно в это время. На этом этапе формирования инвазионного компонента региональной флоры произошло увеличение общего количества семейств с 10 до 14, а также число представителей семейств Asteraceae (на 7 видов), Rosaceae (на 4 вида), Fabaceae (на 2 вида), Brassicaceae и Onagraceae (по 1 виду). Появились 
также виды семейств Balsaminaceae (Impatiens glandulifera Royle, 1998 г., OHHI; I. parviflora DC, 2004 г., MW 0434718), Asclepiadaceae (Asclepias syriaca L., 2008 г., БелГУ), Cucurbitaceae (Echinocystis lobata Torr. et Gray, 1993 г., ЦЧЗ), Nelumbonaceae (Nelumbo nucifera Gaertn., 2016 г. БелГУ), Oxalidaceae (Oxalis stricta L., 1995 г., OHНI), Tiliaceae (Tilia $\times$ europaea L., 2016 г., BELZ), Ulmaceae (Ulmus pumila L., 2002 г., MW 0316887).

Произошло увеличение травянистых поликарпиков (на 6 видов), деревьев (на 5 видов), однолетников (на 4 вида), травянистых монокарпиков и кустарников (на 1 вид в каждой группе), продолжается увеличение числа североамериканских видов (на 10), европейских (на 4) и сибирских (на 1 вид). При этом на 2 вида уменьшается число средиземноморских и на 1 вид азиатских. Впервые в регионе в этот период отмечены южноамериканские Galinsoga ciliata (Rafin.) Blake (2001 г., MOSP), G. parviflora Cav. (1995 г., MW 0540073), восточно-понтические Sisymbrium volgense Bieb. ex Fourn. (1997 г., ЦЧЗ) и причерноморско-прикаспийские (Crepis rhoediafolia Bieb. (2010 г., MW 0554153)) виды. Происходит увеличение числа видов-эргазиофитов (на 9) и ксенофитов (на 8 видов) (табл. 1), а также количество натурализовавшихся в регионе растений (на 10 видов), что свидетельствует об увеличении скорости натурализации и инвазии видов на современном этапе формирования флоры.

\section{ОБСУЖДЕНИЕ}

Увеличение количества инвазионных видов растений, занесенных в регион в отмеченные временные периоды, по-видимому, является отражением социально-экономических и исторических событий в жизни региона. Интенсификация процессов заноса чужеродных растений на втором этапе вероятнее всего стало следствием широкомасштабных военных действий в 1942-1943 гг., а впоследствии - результатом восстановления сельского хозяйства и промышленности региона. В это время существенно увеличилось количество и разнообразие нарушенных экотопов из-за распашки полей и сельскохозяйственных угодий, организации и развития инфраструктуры горнорудной промышленности в Белгородской обл. Несмотря на то, что достоверно определить “полемохорность” вида достаточно трудно (Mannerkorpi, 1944; Shcherbakov et al., 2013; Reshetnikova, 2015), а часто и невозможно, влияние глобального перемещения людей, техники, всевозможных грузов на занос чужеродных видов, учитывая масштабность боевых действий, развернувшихся на территории Белгородской обл. во время Великой Отечественной войны, не вызывает сомнений.

Наиболее интенсивным периодом заноса инвазионных видов на территорию региона являет- ся третий (современный) этап формирования инвазионного компонента флоры. С одной стороны, выявление новых для региона видов растений связано с развитием агрохолдингов и горнорудной промышленности, с другой, в какой-то мере, с увеличением активности флористических исследований в регионе.

Таким образом, формирование инвазионного компонента флоры во времени сопровождалось изменениями в таксономической структуре и соотношениях эколого-биоморфологических характеристик. В конечном итоге в спектре увеличилась роль представителей семейств Asteraceae, Rosaceae, Fabaceae. Возросла роль древесных растений.

\section{БЛАГОДАРНОСТИ}

Авторы благодарят к.б.н. Л.В. Рязанову, к.б.н. А.В. Леострина (Ботанический институт им. В.Л. Комарова РАН, г. Санкт-Петербург), к.б.н. Т.Н. Смекалову (Всероссийский институт генетических ресурсов им. Н.И. Вавилова, г. Санкт-Петербург), к.б.н. С.А. Сенатора (Институт экологии Волжского бассейна РАН - филиал Самарского федерального исследовательского центра РАН, г. Тольятти), Н.И. Золотухина (ЦЧЗ им. проф. В.В. Алехина, г. Курск), за помощь в работе с гербарными материалами.

\section{СПИСОК ЛИТЕРАТУРЫ}

[Baranova et al.] Баранова О.Г., Бралгина Е.А., Колдомова Е.А., Маркова Е.М., Пузырев А.Н. 2016. Черная книга флоры Удмуртской Республики. Ижевск. 67 с.

Blackburn T.M., Pyšek P., Bacher S., Carlton J.T., Duncan R.P., Jarošík V., Wilson J.R.U., Richardson D.M. 2011. A proposed unified framework for biological invasions. - Trends Ecol. Evol. 26 (7): 333-339.

https://doi.org/10.1016/j.tree.2011.03.023

[Elenevskii et al.] Еленевский А.Г., Радыгина В.И., Чаадаева Н.Н. 2004. Растения Белгородской области (Конспект флоры). М. 120 с.

Mannerkorpi P. 1944. Uhtuan taistelurintamalle saapuneista tulokaskasveista. - Ann. Bot. Soc. Zool.-Bot. Fenn. Vanamo. 20 (15): 39-51.

[Reshetnikova] Решетникова Н.M. 2015. Путь появления некоторых западноевропейских видов растений в Калужской области - путь следования немецкой армии в 1941-1943 гг. - Рос. журн. биол. инваз. 4: 95-104.

Richardson D.M., Holmes P.M., Esler K.J., Galatowitsch S.M., Stromberg J.C., Kirkman S.P., Pyšek P., Hobbs R.J. 2007. Riparian vegetation: degradation, alien plant invasions, and restoration prospects. - Divers. Distrib. 13 (1): $126-139$. https://doi.org/10.1111/j.1366-9516.2006.00314.x

[Senator et al.] Сенатор С.А., Тохтарь В.К., Курской А.Ю. 2017. Материалы к флоре Белгородской области. - 
Бот. журн. 102 (5): 671-678.

https://doi.org/10.1134/S0006813617050076

[Shcherbakov et al.] Щербаков А.В., Киселева Л.Л., Панасенко Н.Н., Решетникова Н.М. 2013. Растения живые следы пребывания группы армий “Центр" на русской земле. - В сб.: Материалы межрег. конф. “Флора и растительность Центрального Черноземья - 2013”. Курск. С. 198-202.

[Tokhtar, Fomina] Тохтарь B.К., Фомина О.В. 2013. Особенности формирования флор в урбанизированной среде на юго-западе Среднерусской возвышенности. Белгород. $136 \mathrm{c.}$

[Tokhtar, Kurskoi] Тохтарь В.К., Курской А.Ю. 2019. Инвазионные растения юго-запада Среднерусской возвышенности. Белгород. 120 с.
[Tokhtar et al.] Тохтарь В.К., Курской А.Ю., Зеленкова В.Н. 2019. Новые данные к флоре Белгородской области (по материалам 2018 г.). - Бюлл. МОИП. Отд. биол. 124 (3): 67-69.

[Vinogradova et al.] Виноградова Ю.К., Майоров С.Р., Хорун Л.В. 2010. Черная книга флоры Средней России: чужеродные виды растений в экосистемах Средней России. М. 512 с.

[Vinogradova et al.] Виноградова Ю.К., Майоров С.Р., Нотов А.А. 2011. Черная книга флоры Тверской области: чужеродные виды растений в экосистемах Тверского региона. М. 292 с.

Vinogradova Yu.K., Pergl J., Essl F., Hejda M., van Kleunen M., Regional Contributors, Pyšek P. 2018. Invasive alien plants of Russia: insights from regional inventories. - Biol. Invasions. 20 (8): 1931-1943. https://doi.org/10.1007/s10530-018-1686-3

\title{
PECILIARITIES OF FORMATION OF INVASIVE COMPONENT OF BELGOROD REGION FLORA DURING THE 170-YEAR PERIOD
}

\author{
V. K. Tokhtar ${ }^{a, \#}$ and A. Yu. Kurskoy, ${ }^{a, \#}$ \\ ${ }^{a}$ Belgorod State National Research University \\ Pobedy Str., 85, Belgorod, 308015, Russia \\ "e-mail:tokhtar@bsu.edu.ru \\ \#\#-mail: kurskoy@bsu.edu.ru
}

\begin{abstract}
The article presents results of the study of the formation of invasive component of flora in the southwest of the Central Russian Upland over a 170-year period. From 2011 to 2019 more than 200 natural habitats in the region were studied and the species composition of the invasive component (totally 78 species) was identified. Based on the study of herbarium specimens from 12 Herbaria, it was found that the appearance of species which have become invasive at the present stage of development of the region's phytobiota was occurring unevenly. The dynamics of the appearance of invasive species in the southwest of the Central Russian Upland can be divided into three stages: 1. Appearance of alien species (1850-1929); 2. Initial adaptation and distribution of the alien plants (1930-1989); 3. Intensification of introduction and invasion of species (19902019). The analysis conducted by the authors at different stages of the formation of the invasive component of the flora indicates that over the 170-year period there were significant changes in the ratios of various groups of invasive species. Changes in the structure of the invasive component of flora are primarily related to human economic activity, and intensity of anthropogenic impact on natural ecosystems.
\end{abstract}

Keywords: southwest of the Central Russian Upland, Belgorod Region, alien plant species

\section{ACKNOWLEDGEMENTS}

We sincerely thank L.V. Ryazanova, A.V. Leostrin (Komarov Botanical Institute RAS, St. Petersburg), T.N. Smekalova (Vavilov All-Russian Institute of Genetic Resources, St. Petersburg), S.A. Senator (Institute of Ecology of Volga Basin RAS, Tolyatti), N.I. Zolotukhin (Central Chernozem State Natural Biosphere Reserve named after Professor V.V. Alekhin, Kursk), for assistance in working with herbarium.

\section{REFERENCES}

Baranova O.G., Bralgina E.A., Koldomova E.A., Markova E.M., Puzyrev A.N. 2016. Chernaya kniga flory Udmurtskoi Respubliki [Black book of flora of the Udmurt Republic]. Izhevsk. 67 p. (In Russ.).
Blackburn T.M., Pyšek P., Bacher S., Carlton J.T., Duncan R.P., Jarošík V., Wilson J.R.U., Richardson D.M. 2011. A proposed unified framework for biological invasions. - Trends in Ecology and Evolution. 26 (7): 333-339. https://doi.org/10.1016/j.tree.2011.03.023

Elenevskii A.G., Radygina V.I., Chaadaeva N.N. 2004. Rasteniya Belgorodskoi oblasti (Konspekt flory) [Plants of the Belgorod region (Synopsis of the flora)]. Moscow. 120 p. (In Russ.).

Mannerkorpi P. 1944. Uhtuan taistelurintamalle saapuneista tulokaskasveista. - Ann. Bot. Soc. Zool.-Bot. Fenn. Vanamo. 20 (15): 39-51.

Reshetnikova N.M. 2015. The path of the appearance of some Western European plant species in the Kaluga region - the path of the German army in 1941-1943. Russian J. Biol. Invasions. 4: 95-104 (In Russ.). 
Richardson D.M., Holmes P.M., Esler K.J., Galatowitsch S.M., Stromberg J.C., Kirkman S.P., Pyšek P., Hobbs R.J. 2007. Riparian vegetation: degradation, alien plant invasions, and restoration prospects. - Diversity and Distribution. 13 (1): 126-139. https://doi.org/10.1111/j.1366-9516.2006.00314.x

Senator S.A., Tokhtar V.K., Kurskoy A.Yu. 2017. Materials for the flora of the Belgorod region. - Botanicheskii zhurnal. 102 (5): 671-678 (In Russ.). https://doi.org/10.1134/S0006813617050076

Shcherbakov A.V., Kiseleva L.L., Panasenko N.N., Reshetnikova N.M. 2013. Rasteniya - zhivye sledy prebyvaniya gruppy armii "Tsentr" na russkoi zemle [Plants are living traces of the army group Center's presence on Russian soil]. - In: Flora i rastitel'nost' Tsentral'nogo Chernozem'ya. Materialy mezhregional'noi nauchnoi konferentsii. Kursk. P. 198-202 (In Russ.).

Tokhtar V.K., Fomina O.V. 2013. Osobennosti formirovaniya flor $\mathrm{v}$ urbanizirovannoi srede na yugo-zapade Srednerusskoi vozvyshennosti: monografiya [Features of flora formation in the urbanized environment in the South-West of the Central Russian upland]. Belgorod. 136 p. (In Russ.).

Tokhtar V.K., Kurskoi A.Yu. 2019. Invazionnye rasteniya yugo-zapada Srednerusskoi vozvyshennosti [Invasive plants of the Southwest of the Central Russian upland]. Belgorod. 120 p. (In Russ.).

Tokhtar V.K., Kurskoy A.Yu., Zelenkova V.N. 2019. Novye dannye $\mathrm{k}$ flore Belgorodskoi oblasti (po materialam 2018 g.) [New data on the flora of the Belgorod region (based on materials from 2018)]. - Bulletin MOIP. Otd. biol. 124 (3): 67-69 (In Russ.).

Vinogradova Yu.K., Mayorov S.R., Khoroon L.V. 2010. Chernaya kniga flory Srednei Rossii: chuzherodnye vidy rastenii v ekosistemakh Srednei Rossii [Black book of the flora of Central Russia: alien plant species in the ecosystems of Central Russia]. Moscow. 512 p. (In Russ.).

Vinogradova Yu.K., Mayorov S.R., Notov A.A. 2011. Chernaya kniga flory Tverskoi oblasti: chuzherodnye vidy rastenii v ekosistemakh Tverskogo regiona [Black book of flora of the Tver region: alien plant species in the ecosystems of the Tver region]. Moscow. 292 p. (In Russ.).

Vinogradova Yu.K., Pergl J., Essl F., Hejda M., van Kleunen M., Regional Contributors, Pyšek P. 2018. Invasive alien plants of Russia: insights from regional inventories. - Biol. Invasions. 20 (8): 1931-1943. https://doi.org/10.1007/s10530-018-1686-3 